\title{
Crystal Structure and Some Properties of the Compound, $\mathrm{Zr}_{3} \mathrm{Al}$
}

\author{
by J. H. Keeler and J. H. Mallery
}

$\mathbf{T}$ $\mathrm{HE}$ crystal structure of $\mathrm{Zr}_{3} \mathrm{Al}$, the compound richest in zirconium ( 91.03 pct $\mathrm{Zr}$ by weight) in the system $\mathrm{Zr}-\mathrm{Al}$, has been found to be ordered facecentered-cubic. This compound is of particular interest, since it is encountered as the precipitated phase in potentially useful zirconium-rich alloys. It forms peritectoidally from body-centered-cubic zirconium and $\mathrm{Zr}_{2} \mathrm{Al}$ at about $975^{\circ} \mathrm{C}$. The $\mathrm{Zr}-\mathrm{Al}$ constitution diagram has been reported by McPherson and Hansen. ${ }^{1}$

For the primary determination a $100 \mathrm{~g}$ ingot was prepared by arc-melting in a water-cooled copper crucible under purified argon. The raw materials were crystal-bar zirconium (a purity of better than 99.7 pct) and spectroscopically pure aluminum. The ingot was double melted, examined metallographically, and found to be quite uniform as shown in Fig. 1. The hardness of the as-cast button was VHN 390 to 445 .

A 20 mil diam specimen was prepared from annealed $\left(900^{\circ} \mathrm{C}\right)$ filings of $\mathrm{Zr}_{8} \mathrm{Al}$. The specimen was mounted in a $5 \mathrm{~cm}$ radius powder camera and an $8 \mathrm{hr}$ exposure was taken using copper radiation with a nickel filter.

The structure of the compound $\mathrm{Zr}_{\mathrm{s}} \mathrm{Al}$ was found to be ordered face-centered-cubic of the $\mathrm{Cu}_{3} \mathrm{Au}$ type, with an $a_{\mathrm{o}}$ value of $4.372 \pm 0.003 \AA$. Its calculated density is $5.976 \pm 0.013 \mathrm{~g}$ per $\mathrm{cu} \mathrm{cm}$. The relative intensities for the lines were calculated using the formula

$$
I \propto \frac{1+\cos ^{2} 2 \theta}{\sin ^{2} \theta \cos \theta} \cdot p \cdot / F^{2} /
$$

where $\frac{1+\cos ^{2} 2 \theta}{\sin ^{2} \theta \cos \theta}$ is the Lorentz polarization factor, $p$ is the multiplicity factor, and $F$ is the structure factor. The X-ray data are given in Table I.

J. H. KEELER, Member AIME, and J. H. MALLERY are associated with Alloy Studies Research, Research Laboratory, General Electric Co., Schenectady.

TN 257E. Manuscript, Oct. 22, 1954.
Fig. 1-Micrograph of as-cast $\mathrm{Zr}_{3} \mathrm{Al}$ shows a fairly uniform structure. Bright field, etched in $\mathrm{HNO}_{3}, \mathrm{HF}$, and glycerine. X100. Area reduced approximately 20 pct for reproduction.

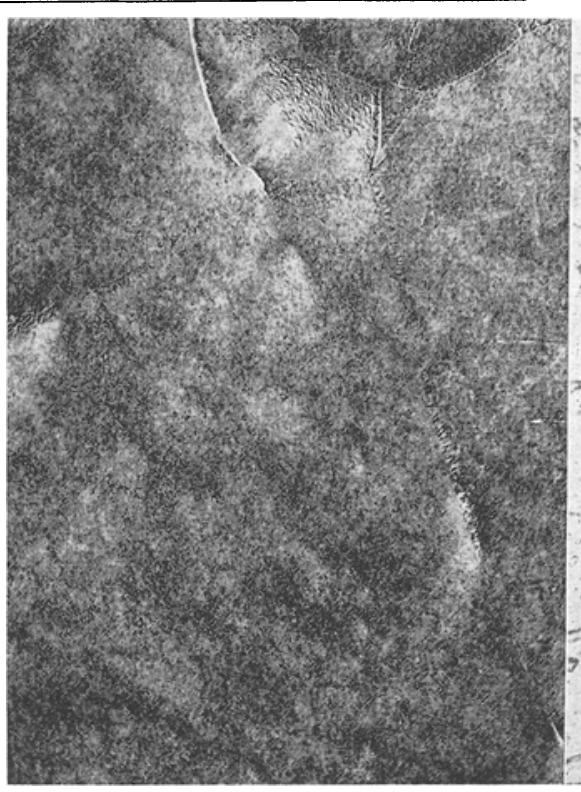

Table I. X-Ray Data for Compound $\mathrm{Zr}_{3} \mathrm{Al}$

\begin{tabular}{|c|c|c|c|c|}
\hline$h k l$ & $\underset{d}{\text { Calculated }}$ & $\underset{d}{\text { Observed }}$ & $\begin{array}{l}\text { Calculated } \\
\text { Intensity }\end{array}$ & $\begin{array}{l}\text { Observed } \\
\text { Intensity }\end{array}$ \\
\hline $\begin{array}{c}100 \\
110 \\
111 \\
200 \\
210 \\
211 \\
220 \\
\mathbf{2 0 0 , 2 2 1} \\
310 \\
311 \\
222 \\
320 \\
321 \\
400 \\
\mathbf{4 1 0 , 3 2 2} \\
\mathbf{4 1 1 , 3 3 0} \\
\mathbf{3 3 1} \\
\mathbf{4 2 0} \\
\mathbf{4 2 1} \\
\mathbf{3 3 2} \\
\mathbf{4 2 2} \\
\mathbf{5 0 0 , 4 3 0} \\
\mathbf{5 1 0 , 4 3 1} \\
\mathbf{5 1 1 , 3 3 3} \\
\mathbf{5 2 0 , 4 3 2} \\
\mathbf{5 2 1}\end{array}$ & $\begin{array}{l}4.372 \\
3.091 \\
2.524 \\
2.186 \\
1.955 \\
1.785 \\
1.546 \\
1.457 \\
1.383 \\
1.318 \\
1.262 \\
1.212 \\
1.168 \\
1.093 \\
1.060 \\
1.030 \\
1.003 \\
0.9776 \\
0.9540 \\
0.9321 \\
0.8924 \\
0.8744 \\
0.8574 \\
0.8414 \\
0.8119 \\
0.7982\end{array}$ & $\begin{array}{l}4.38 \\
3.09 \\
2.52 \\
2.18 \\
1.95 \\
1.78 \\
1.54 \\
1.46 \\
1.38 \\
1.32 \\
1.26 \\
1.22 \\
1.17 \\
1.09 \\
1.06 \\
1.03 \\
1.003 \\
0.977 \\
0.953 \\
0.931 \\
0.892 \\
0.873 \\
0.857 \\
0.841 \\
0.812 \\
0.798\end{array}$ & $\begin{array}{r}227 \\
186 \\
1543 \\
760 \\
97 \\
71 \\
470 \\
470 \\
9 \text { to } 35 \\
57 \\
517 \\
154 \\
38 \\
39 \\
79 \\
14 \text { to } 14 \\
13 \text { to } 7 \\
276 \\
267 \\
26 \\
14 \\
279 \\
4 \text { to } 15 \\
16 \text { to } 31 \\
336 \text { to } 112 \\
45 \text { to } 45 \\
55\end{array}$ & $\begin{array}{c}\text { Medium } \\
\text { Medium } \\
\text { Very strong } \\
\text { Strong } \\
\text { Weak } \\
\text { Weak } \\
\text { Strong } \\
\text { Weak } \\
\text { Weak } \\
\text { Strong } \\
\text { Medium to strong } \\
\text { Very weak } \\
\text { Weak } \\
\text { Medium } \\
\text { Very weak } \\
\text { Very weak } \\
\text { Medium to strong } \\
\text { Medium to strong } \\
\text { Very weak } \\
\text { Very weak } \\
\text { Strong } \\
\text { Very very weak } \\
\text { Very weak } \\
\text { Strong } \\
\text { Weak } \\
\text { Weak }\end{array}$ \\
\hline
\end{tabular}

The compound has exhibited plasticity when present as particles in a matrix of $\alpha$ zirconium. During hot working at about $900^{\circ} \mathrm{C}$, the compound has been found to deform plastically to the extent that some of the particles exhibit a length-to-width ratio greater than 4:1 as shown in Fig. 2. In answer to the discussion of ref. 1, McPherson and Hansen pointed out that the compound may be cold rolled and reduced as much as 33 pct.

$\mathrm{Zr}_{3} \mathrm{Al}$ has also been found ${ }^{2}$ under certain conditions to precipitate in lamellar form at grain boundaries of the $\alpha$ phase of hexagonal-close-packed zirconium.

\section{Acknowledgment}

This work was carried out under Contract W-31109-Eng 52 for the United States Atomic Energy Commission.

\footnotetext{
1 D. J. McPherson and M. Hansen: Trans. ASM (1954) 46, p. 354. 2 J. H. Keeler: Trans. ASM (1954) 46, p. 373.
}

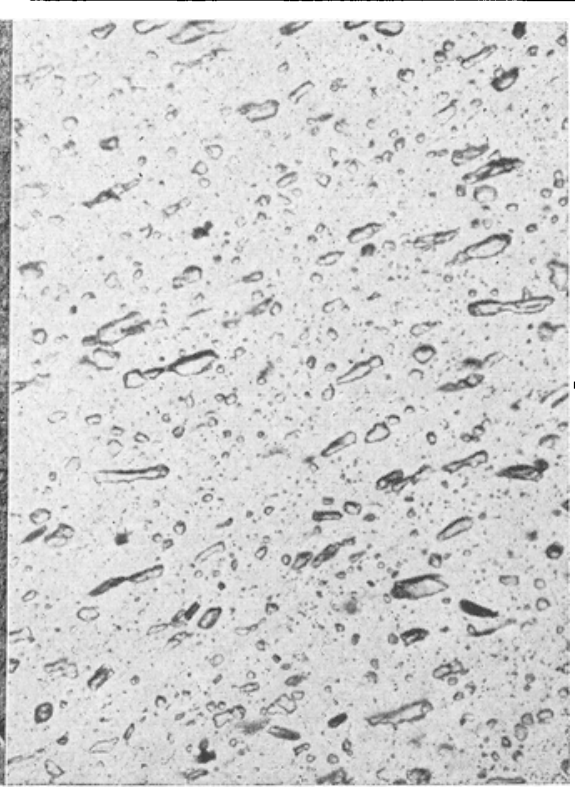

Fig. 2-Micrograph of specimen shows elongated particles of $\mathrm{Zr}_{3} \mathrm{Al}$ in a matrix of $\alpha$ zirconium. The specimen of 10 atomic pct $\mathrm{Al}$ in zirconium was hot rolled at $900^{\circ} \mathrm{C}$ and then annealed $1 \mathrm{hr}$ at $850^{\circ} \mathrm{C}$. Bright field, etched in $\mathrm{HNO}_{3}, \mathrm{HF}$, and $\mathrm{H}_{2} \mathrm{O}$. X500. Area reduced approximately 20 pct for reproduction. 